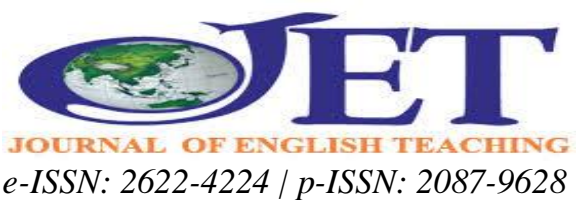

\title{
The Effects of Implementing Vocabulary Journals into Main Course Classes on Student Success at a Private University
}

\author{
Tulin Turnuk \\ tturnuk@hotmail.com \\ Istanbul Medeniyet University School of Foreign Languages, Turkey
}

\begin{abstract}
Vocabulary learning is one of the most difficult components of foreign language education. Therefore, students are in need of some strategies to cope with it and keeping vocabulary journals is one of these particular strategies. This study examined the vocabulary journals kept by the preparatory school students of a private university to determine the effects of them on learner success and learner autonomy as well as the attitudes of students and instructors towards them. A mixed method approach in which qualitative data was supported by quantitative data was applied to totally 346 participants. The findings of the study provide relevant information and insight for the instructors and administrators who aim to enhance vocabulary learning and plan to implement vocabulary journals into their own educational systems.
\end{abstract}

Keywords: vocabulary journal, vocabulary learning, retention, learner autonomy, homework

\section{INTRODUCTION}

Vocabulary learning has been a fundamental issue in the history of English language teaching, especially from the 1990s on (see e.g. Schmitt \&Schmitt, 1995). It is extremely important for university preparation year students as they will have to read long academic texts and write lengthy passages when they proceed to their departments. However, students tend to have difficulties in learning and remembering the large amount of vocabulary covered in the curriculum.

Rote memorization, the oldest technique of vocabulary learning and is based on lists of words with mother tongue equivalent meaning, has been proven to be inefficient. According to previous research (see e.g. McCrostie, 2007; Walters \& Bozkurt, 2009; Uzun, 2013) keeping vocabulary journals has certain advantages over other strategies for two reasons. Firstly, keeping vocabulary journals can be a beneficial strategy to foster vocabulary learning by making students put some cognitive effort in it for better retention. Secondly, vocabulary journals foster learner autonomy.

A vocabulary journal is an ongoing personal collection of key vocabulary items with additional information such as an illustration, an example sentence, synonyms/antonyms and collocations to increase language learners' understanding of words and to ensure that they are going to use these particular words in their subsequent language practice. It can take various forms: a usual notebook, single pages, leafletbinders, or electronic platforms. Previous researchers studied different aspects of vocabulary journals separately. For instance, Schmitt and Schmitt (1995) emphasized that learners have to choose what words to include in their vocabulary journals by themselves in order to be fully autonomous. They also stated that it is required to give a step by step training to learners before they start keeping journals. On the other hand, 
Walters and Bozkurt (2009) suggested that vocabulary journals should be integrated into classroom studies.

The current study examined the effect of implementing vocabulary journals with predetermined word lists into main course classes without any prior training on student success at a private university in Istanbul, Turkey along with students' and instructors' attitudes towards them, which had not been examined together in many research studies.

\section{LITERATURE REVIEW}

As Read (2004) points out, "traditional techniques of presenting new words in class or requiring students to memorize lists of vocabulary items seem old-fashioned in the context of current task-based language programs" (p. 146). Some common strategies to remember the words are rote memorization, using pictures, semantic mapping and linking the old knowledge with the new. Keeping vocabulary journals has certain advantages over other strategies according to previous research studies. "Vocabulary notebooks offer learners the chance to expand their repertoire of vocabulary learning strategies, and they have the potential to enhance vocabulary learning, perhaps more than any other single vocabulary learning strategy used on its own" (Walters \& Bozkurt, 2009, p. 404). McCrostie(2007) states that vocabulary journals serve two different purposes. The first one is to have better retention with more cognitive effort. In other words, they help remembering words as they incorporate new and old knowledge, which increases retention.

Alexander, Argent, and Spencer (2008) remark that "research into vocabulary learning has found that in order for a vocabulary item to be acquired, it must first be noticed, and then needs to be retrieved at spaced intervals" (p. 168). In line with this, Schmitt (2002) states vocabulary is best retained with repeated exposures to words and vocabulary journals serve this function since students need to go back to the words they have already written to add some new information. "The most efficient learning happens when learners are concentrating their mental resources at the task at hand" (Schmitt \&Schmitt, 1995, p. 136). In Craik and Lockhart's (1972) depth of processing hypothesis, this recycling procedure helps vocabulary be transferred to long-term memory to be stored.

According to McCrostie (2007), the second purpose of vocabulary journals is to increase learner autonomy. Other researchers also support this idea. Students' "individual efforts to discover and develop meaning enhance both their learning of vocabulary and their independence from the teacher" (Schmitt \& Schmitt, 1995, p.139). According to research findings, "keeping vocabulary notebooks necessitates learners to take more responsibility for their own learning process and become more autonomous" (Uzun, 2013, p. A-2). Moreover, as Schmitt and Schmitt (1995) and Schmitt (2002) state, vocabulary journals provide learners with independence and through keeping vocabulary journals students take the responsibility of their own learning and become autonomous learners, which is a crucial $21^{\text {st }}$ century skill.

As Allen (1983) expresses, vocabulary journals make vocabulary learning more systematic. When students keep vocabulary journals, they understand the meaning of vocabulary and according to Allen this is the first step of learning words. As Craik and Tulvig (1975) pointed out, "it seems clear that attention to the word's meaning is a necessary prerequisite of good retention" (p. 269). However, knowing the meaning is not enough to fully learn a word, as Makarchuk (2006) remarked "features of the word beyond meaning are essential for genuine understanding" (p. 97).In Oxford and 
Crookall's (1990) opinion, "knowing an L2 word involves not just the ability to recognize the word or match the word with its L1 counterpart, if such exists; knowing an L2 word also involves being able to use the L2 word communicatively in any of the four main language skills" (p. 9). They continue to state that bilingual dictionaries are not efficient because they inhibit learners from thinking directly in L2. Modern types of monolingual dictionaries, on the other hand, provide much richer context to help learners remember vocabulary.

Recording vocabulary in a format that includes functional purpose, word class, collocations, and grammar patterns preserves the contextual aspects of the items. Trying to record vocabulary in a simplified, 'cleaned-up' form may discard valuable clues about the way the item operates in texts" (Alexander, Argent \& Spencer, 2008, p. 170). Using words in sentences is a crucial step "if the goal is productive capability, switching to activities which require production of the target words, such as using it in written sentences, will improve the chances of future recall" (Schmitt \& Schmitt, 1995, p. 135). Using words in sentences provides contextualisation of words and help students realize that words can have different meanings according to different contexts (Nation, 1974).

It is difficult for students to provide the relevant information about words in lower levels; however, they have to start keeping a vocabulary journal as soon as the academic year starts. Incorporating a vocabulary notebook program into the curriculum right from the start of the term would give students the chance to develop a useful vocabulary learning habit, and perhaps increase the chances of its being used throughout the language learning process (Walters \& Bozkurt, 2009, p. 420).According to Craik and Lockhart (1972), whereas words are stored phonemically in the short-term memory, they are stored semantically in long-term memory. The "depth of processing hypothesis" of them states that deeper semantic and cognitive analysis enhances understanding and learning.

The aim of the current study was to analyse the effects of vocabulary journals with pre-determined words, without special training and without any integration into classroom activities in particular.

\section{Research Questions}

To this aim, the following research questions were formulated:

1. What are the effects of implementing vocabulary journals on student achievement in vocabulary learning and learner autonomy?

2. What are the students' and instructors' attitudes towards vocabulary journals?

\section{METHOD}

This mixed-method study was a non-experimental and interpretive case study which was based on both qualitative and quantitative approaches in an embedded design in order to gain a richer and deeper understanding of the phenomenon. Qualitative analysis was supported by quantitative data which were all collected in the field. The study was part of the regular teaching in the institution and no parts of the program were changed to accommodate it.

The participants of this study consisted of 3 administrators, 16 main course instructors, 255 new students, and 72 repeater students from the prep department. Convenience sampling was used for the students and instructors, that is to say, participants were selected out of 1000 new students, 110 repeater students, and 29 main course instructors because they were willing and available to be studied. 


\section{Context}

This study was conducted in a private university where the medium of instruction is English in all departments. In the preparatory school, there are four modules (Alpha [Beginner], Beta [Elementary], Gamma [Pre-Intermediate, and Delta [Intermediate]) in which students are placed after taking the level assessment test when they first come to the school. The exit level of the prep school is B1 according to the Common European Framework of References for Languages (CEFR). Delta module is composed mostly of repeater students. There are 23-25 students in each class and they study English for 27 hours a week in eight-week modules. Their ages range from 17 to 20 . The students are expected to keep vocabulary journals in all modules by being given a list of 20 words to learn every week.

These are either frequently used words or words from their course books. Journals consist of single pages so that "pages can be taken out and moved around to facilitate expanding rehearsal; pages with better-known words can be put further back in the binder, and lesser known words put towards the front" (Schmitt \& Schmitt, 1995, p.137). Vocabulary journals have four columns for the beginner, Alpha, level: In the first one, students are supposed to write the part of speech and the optional Turkish meaning for their personal studies (see Figure 1). The second column is allocated for the English meaning. Antonyms and synonyms are to be written in the third column and the last column is for example sentences. In the higher levels, another column is added for collocations and information about affixes is added to antonyms and synonyms under the title of 'miscellaneous'.

Vocabulary journals do not replace explicit vocabulary instruction but support it. They are checked by the main course instructors every week to see whether the information students have put is accurate or not. The journals are graded out of 20 according to a rubric and feedback is given, which takes a high amount of time. The journals are collected on Monday and given back by the following Friday. In order to encourage students to keep the journals regularly, $70 \%$ of the Main Couse portfolio grade is allocated to them as motivation is a key factor in any kind of learning. However, no specific class time is set aside to incorporate vocabulary journals into classroom activities such as learners' sharing the information they have gathered with their classmates and no specific training is provided before they start keeping the journals.

\section{Data Collection Procedures}

Quantitative data was collected using this procedure: The new students and repeater students were given two different Likert scale questionnaires (Appendix 3 and 4) prepared by the researcher herself as they are quick and efficient and as the responses are easily quantifiable. Another advantage of Likert scale questionnaires is that they accommodate room for neutral feelings. The questions were translated into the students' L1, Turkish, for beginner and elementary levels. Finally, the deputy heads analysed the exam grades in comparison with the grades in the previous year in order to determine the effects of keeping vocabulary journals on student success.

For the quantitative data was collected following this process: First, structured interviews were conducted with the administrators (Appendix 1), becausestructured interviews provide a more comprehensive view of an issue and are more efficient when each participant answers the same questions so that the responses can be compared. Second, the main course instructors were given open-ended questionnaires which are 
ideal for qualitative research in order to get their genuine opinions (Appendix 2). Only the ones who have been working for the university for at least one year were chosen as they can see the difference, if any, vocabulary journals have created. The meaning of responses was investigated later on by the researcher. Finally, the researcher in her class got the reflections of two students in a short paragraph written in Turkish as they were of the beginner level. One of these students liked keeping vocabulary journals very much whereas the other one hated it.

\section{Data Analysis Procedures}

The qualitative data was analysed descriptively. Firstly, the open-ended questionnaires given to the main course instructors were read and the responses were put into the coding process. There were several helpful suggestions from the colleagues and similar responses were identified and their percentages were calculated. Also, there were different suggestions made by only a single instructor and they were also mentioned in the results. Secondly, interviews with the administrators were transcribed and coded. In particular, the responses related with the implementation process and the expectations from the vocabulary journals were selected in order to give a managerial view. Finally, reflections of the two students were read and coded. Their suggestions were also included in the results section.

The quantitative data collected from the Likert scale student questionnaires were counted and percentages were calculated by hand. Secondly, exam results were analysed in comparison with results of the previous year and success rates were calculated.

\section{FINDING AND DISCUSSION}

As for quantitative data analysis, both new and repeater students mostly find vocabulary journals and the feedback given by the teachers beneficial for their learning and retaining English vocabulary and they hope to get better marks thanks to keeping vocabulary journals. On the other hand, $30.88 \%$ of total students confess that it is timeconsuming to fill in the journals.

When exam results were compared with the previous year's, however, only $2 \%$ and $4 \%$ increase was observed in Alpha and Beta level reading comprehension respectively and other than that no improvement in exam grades was seen, but it should be kept in mind that there are various parameters and variables in the field of education and the student profile in one academic year cannot be considered the same as the previous year.

When it comes to qualitative data analysis, with regard to the first research question, $50 \%$ of the main course instructors agreed that vocabulary journals made a positive change in the lexical competence of the students as they tried to use the target words in their sentences. This idea can be seen in the comment below:

"My students started using the words during class hours and they try to make sentences with them in pair and group work activities." 
Table 1:

Analysis of Data Collected from New Students

\begin{tabular}{lccccc}
\hline & $\begin{array}{c}\text { Strongly disagree } \\
\text { New Sts }\end{array}$ & $\begin{array}{c}\text { Disagree } \\
\text { New Sts }\end{array}$ & $\begin{array}{c}\text { Neutral } \\
\text { New Sts }\end{array}$ & $\begin{array}{c}\text { Agree } \\
\text { New Sts }\end{array}$ & $\begin{array}{c}\text { Strongly Agree } \\
\text { New Sts }\end{array}$ \\
\hline Q1 & 13 & 18 & 67 & 98 & 59 \\
$\%$ & 5,09 & 7,1 & 26,2 & 38,4 & 23,1 \\
Q2 & 48 & 55 & 74 & 36 & 42 \\
$\%$ & 18,8 & 21,5 & 29,01 & 14,1 & 16,4 \\
Q3 & 12 & 19 & 55 & 111 & 58 \\
$\%$ & 4,7 & 7,45 & 21,5 & 43,5 & 22,7 \\
Q4 & 20 & 36 & 86 & 54 & 37 \\
$\%$ & 7,8 & 14,1 & 33,7 & 21,17 & 14,5 \\
Q5 & 36 & 37 & 41 & 92 & 49 \\
$\%$ & 14,1 & 14,5 & 16 & 36 & 19,2 \\
Q6 & 38 & 43 & 44 & 76 & 54 \\
$\%$ & 14,9 & 16,8 & 17,2 & 29,8 & 21,1 \\
Q7 & 15 & 71 & 27 & 22 & 20 \\
$\%$ & 9,6 & 27,8 & 10,5 & 8,6 & 7,8 \\
Q8 & 27 & 26 & 27 & 86 & 89 \\
$\%$ & 10,5 & 10,1 & 10,5 & 33,7 & 34,9 \\
Q9 & 19 & 24 & 74 & 80 & 58 \\
$\%$ & 7,4 & 9,4 & 29 & 31,3 & 22,7 \\
Q10 & 97 & 47 & 43 & 44 & 24 \\
$\%$ & 38 & 18,4 & 16,8 & 17,2 & 9,41 \\
Q11 & 47 & 34 & 54 & 44 & 76 \\
$\%$ & 18,4 & 13,3 & 21,1 & 17,2 & 29,8 \\
Q12 & 76 & 56 & 53 & 36 & 34 \\
$\%$ & 29,8 & 21,9 & 20,7 & 14,1 & 13,3 \\
\hline & & & & & \\
\hline
\end{tabular}

However, the others had some opposition saying that the students still did not know the meaning of words when they were asked in class as they did not do any revision. This criticism can be seen in the comment below:

"As long as they do not go over the journals, there will not be any improvement."

Also, some main course instructors pointed out that the success of vocabulary journals could not be measured as vocabulary parts of the exams were out of just 5 points whereas some other instructors stated that keeping journals could be of great help for reading comprehension and writing:

"Thanks to vocabulary journals, they will understand the texts more easily and they will write better paragraphs or essays." 
Table 2:

Analysis of Data from Repeater Students

\begin{tabular}{|c|c|c|c|c|c|}
\hline & $\begin{array}{c}\text { Strongly } \\
\text { Disagree } \\
\text { Repeater Sts }\end{array}$ & $\begin{array}{c}\text { Disagree } \\
\text { Repeater Sts }\end{array}$ & $\begin{array}{c}\text { Neutral } \\
\text { Repeater Sts }\end{array}$ & $\begin{array}{c}\text { Agree } \\
\text { Repeater Sts }\end{array}$ & $\begin{array}{c}\text { Strongly Agree } \\
\text { Repeater Sts }\end{array}$ \\
\hline Q1 & 4 & 7 & 30 & 19 & 12 \\
\hline$\%$ & 5,5 & 9,7 & 41,6 & 26,3 & 16,6 \\
\hline Q2 & 7 & 21 & 21 & 16 & 7 \\
\hline$\%$ & 9,7 & 29,1 & 29,1 & 22,2 & 9,7 \\
\hline Q3 & 7 & 5 & 19 & 32 & 9 \\
\hline$\%$ & 9,7 & 6,9 & 26,3 & 44,4 & 12,5 \\
\hline Q4 & 4 & 13 & 18 & 26 & 11 \\
\hline$\%$ & 5,5 & 18 & 25 & 36 & 15,2 \\
\hline Q5 & 8 & 9 & 23 & 22 & 10 \\
\hline$\%$ & 11,1 & 12,5 & 31,9 & 30,5 & 13,8 \\
\hline Q6 & 3 & 9 & 22 & 26 & 12 \\
\hline$\%$ & 4,1 & 12,5 & 30,5 & 36,1 & 16,6 \\
\hline Q7 & 5 & 12 & 18 & 19 & 18 \\
\hline$\%$ & 6,9 & 16,6 & 25 & 26,3 & 25 \\
\hline Q8 & 3 & 9 & 26 & 19 & 15 \\
\hline$\%$ & 4,1 & 12,5 & 36,1 & 26,3 & 20,8 \\
\hline Q9 & 15 & 14 & 25 & 17 & 1 \\
\hline$\%$ & 20,8 & 19,4 & 34,7 & 23,6 & 1,3 \\
\hline Q10 & 18 & 17 & 18 & 17 & 2 \\
\hline$\%$ & 25 & 23,6 & 25 & 23,6 & 2,7 \\
\hline Q11 & 19 & 12 & 24 & 7 & 10 \\
\hline$\%$ & 26,3 & 16,6 & 33,3 & 9,7 & 13,8 \\
\hline
\end{tabular}

They also added that vocabulary journals could contribute to the portfolio grade:

"When a student completes his/her journal without any missing words, he/she can get at least 70 points."

Finally, $60 \%$ of the main course instructors shared the opinion that vocabulary journals will have some benefits for students in terms of self-discipline and being organized and that they will remember words more easily when they proceed to their departments. This opinion can be seen in the comments below:

"Vocabulary journals do not only teach words but also they develop a student's habit of doing assignments on time and being organized. This is one of the key things that will make them successful undergraduate students."

"They will have better vocabulary knowledge which they cannot forget easily since they have used the words in different ways such as looking up the meaning, dealing with antonyms and synonyms, etc."

In terms of the second research question, almost all main course instructors agreed that keeping vocabulary journals was a beneficial strategy to learn new words as it created a habitual medium and that they fostered learner autonomy as well as the sense of responsibility. This opinion can be seen in the comments below: 
"Keeping vocabulary journals has enabled students to take a good control of their vocabulary learning. Furthermore, it contributes to their overall proficiency."

"It also helps them get autonomous in learning words as they learn how to use dictionaries."

However, the instructors had some suggestions. Firstly, some main course instructors remarked that it should not be obligatory to keep the journals saying that if the aim was learner autonomy, then it should be an optional out of class study and one of the instructors even suggested that there should not be a strict format to keep it. Additionally, one of the instructors expressed her opinion that vocabulary journals should not be composed of predetermined words for actual student autonomy. This criticism can be seen in the following comment:

"However, we ask students to keep the journal of predetermined vocabulary items. I believe this is not a brilliant idea to put into action. Another flaw of these journals is assessing them according to a rubric."

Secondly, nearly all the instructors emphasized that vocabulary journals were effective only in the upper levels with more grammatical and lexical knowledge to keep them consciously. This point can be seen in the comments below:

"In the beginner level, it is just a copying exercise from a dictionary rather than practising with the target vocabulary."

"If the students could understand what they read and formed their own sentences instead of using example sentences taken from the dictionary, it would be useful."

Thirdly, $50 \%$ of the instructors mentioned the burden it put on teachers' and students' shoulders with 20 words for a week which were said to be too many:

"It takes too much time to grade and evaluate them."

They added that this time could be used for something more useful such as doing some exercises from the workbook. The last but not least criticism was about students' attitudes towards keeping vocabulary journals saying that they did not take it seriously and did it just for the sake of doing it and that some students copied and pasted from one another, which was not desired by the administrators.

The two students who wrote down their reflections agreed that keeping vocabulary journals was a highly beneficial strategy to learn and remember words. However, they complained about the fact that it was very time-consuming. They also added that none of the students kept it willingly and that there could be almost no benefit from something done out of an obligation. Therefore, they suggested that it could be used in a different way such as an activity in class.

Administrators, on the other hand, stated that vocabulary learning was one of the problem areas in foreign language learning, so something had to be done about it. They also emphasized that this was the idea of some instructors in the faculty and the others showed enthusiasm when asked about their opinions. All the administrators believed that vocabulary journals were very beneficial and that they could contribute to the success of students on the condition that they were kept wisely and carefully. They agreed with the instructors in that the effects of vocabulary journals can also be seen in reading comprehension and writing.

To summarize, in the current study it was found out that keeping vocabulary journals was indeed of great help to learn and retain new words as it was stated in previous research studies (e.g. McCrostie, 2007 and Allen, 1983)] although they did not 
have any effect on examination results. In addition, vocabulary journals were observed to have positive impact on fostering learner autonomy and enhancing the sense of responsibility with sharp deadlines each week, which was mentioned by Schmitt and Schmitt (1995) and Uzun (2013) for example. It was also understood that prior training was really necessary as Schmitt and Schmitt (1995) pointed out, because especially in the beginner level it took three weeks for students to comprehend what exactly was expected from them. Furthermore, as the two students writing their reflections emphasized, vocabulary journals might be implemented into classroom study in order to have more effective outcomes, which was remarked by Walters and Bozkurt (2009).

Finally, as a contribution to the study in this field, it was seen that keeping vocabulary journals not only increases the vocabulary knowledge and retention but also enhances reading comprehension skill and writing production and that they increase the success rate also in this way. Another contribution can be the instructors' concern about their work load when vocabulary journals become obligatory in a school system. An additional contribution was the finding that writing an English definition is not suitable for beginner levels as they do not have enough proficiency to see which the definition they are looking for is. The last but not least contribution may be fact that keeping vocabulary journals becomes an unfruitful strategy if learners copy them from one another or right from the dictionary.

\section{Limitations}

As this was a case study, it was carried out within limited boundaries and since convenience sampling was used, it cannot be assured that the participants were the true representatives of the whole population. Furthermore, whether the students gave their answers seriously and consciously in Likert scale questionnaires cannot be guaranteed.

\section{Pedagogical Implications}

Vocabulary learning is a crucial and problematic part of foreign language education. Therefore, learners have to be taught effective strategies to learn new vocabulary items. Keeping vocabulary journals is one of these fruitful strategies, but it is not enough on its own and learners must be made aware of some other strategies such as making associations, creating mind maps, etc.

\section{CONCLUSION AND SUGGESTION \\ Conclusion}

The current study aimed at determining the effects of vocabulary journals on student success and learner autonomy at a private university along with instructors' and students' attitudes towards them. It was found out that keeping a vocabulary journal is a beneficial technique to learn target words as long as they are kept wisely. If they are copied from a peer student or directly from a dictionary, they have no practical outcomes. Furthermore, learners, especially in the beginner and elementary levels, need some prior training until they figure out what exactly they are supposed to do. In addition, beginner level learners should be exempted from writing English definitions since they do not have enough proficiency to comprehend them and as they attempt to write other definitions rather than the definition in their course books. Finally, the study revealed that vocabulary journals have both advantages and disadvantages. While they foster vocabulary knowledge and learner autonomy, they may not have any positive effect on exam results and they also put a burden on teachers' shoulders with the 
checking and grading process. Therefore, all the aspects have to be considered carefully before implementing vocabulary journals into educational systems.

\section{Suggestion}

For further research, different combinations of the factors mentioned previously in the present study may be examined such as pre-determined words with prior training, no pre-determined words with some training, pre-determined words along with classroom implementation, or classroom implementation without a strict format, etc.

\section{REFERENCES}

Alexander, O., Argent, S. \& Spencer, J. (2008). EAP Essentials: A Teacher's Guide to Principles and Practice. Berkshire: Garnet Publishing.

Allen, V.F. (1983). Techniques in Teaching Vocabulary. Oxford: Oxford University Press.

Craik, F.I.M. \& Lockhart, R.S. (1972). Levels of Processing: A Framework for Memory Research. Journal of Verbal Learning and Verbal Behaviour, 11, 671-684. https://www.researchgate.net/publication/200772647_Levels_of_Processing_A_F ramework_for_Memory_Research

Craik, F.I.M \&Tulving, E. (1975).Depth of Processing and the Retention of Words in Episodic Memory. Journal of Experimental Psychology, 104 (3), 268-294. http://bit.ly/2dqnxIN

Makarchuk, D. (2006). Vocabulary Journals: Attitudes and Acquisition in an Adult $\begin{array}{llll}\text { Context. } & \text { English } & \text { Teaching, } & 61\end{array}$ (2), 93-113. http://scholar.google.com.tr/scholar?start=50\&q=fowle+vocabulary\&hl=tr\&as_sd $\mathrm{t}=0,5$

McCrostie, J. (2007). Examining Learner Vocabulary Notebooks. ELT Journal 61 (3), 246-255.https://academic.oup.com/eltj/article-abstract/61/3/246/400103

Oxford, R. \&Crookall, D. (1990, March). Vocabulary Learning: A Critical Analysis of $\begin{array}{lllll}\text { Techniques. } & \text { TESL Canada Journal, } 7 & \text { (2), }\end{array}$ https://teslcanadajournal.ca/index.php/tesl/article/view/566

Read, J. (2004). Research in Teaching Vocabulary. Annual Review of Applied Linguistics, 24, 146-161. http://dx.doi.org/10.1017/S0267190504000078

Schmitt, N. \& D. Schmitt. (1995). Vocabulary Journals: Theoretical Underpinnings and $\begin{array}{lllll}\text { Practical Suggestions. } & \text { ELT Journal, } 49 & \text { (2), 133-143. }\end{array}$ http://dx.doi.org/10.1093/ELT/49.2.133

Schmitt, N. (2002). Vocabulary in Language Teaching. Cambridge: Cambridge University Press.

Uzun, L. (2013). Promoting Vocabulary Learning through Vocabulary Journals: Teaching and Learning Strategies and Gender.Journal of Academic Language \& Learning, 7 (1), A_1A_13.http://www.journal.aall.org.au/index.php/jall/article/viewPDFInterstitial/24 $4 / 158$

Walters, J. \& Bozkurt, N. (2009).The Effect of Keeping Vocabulary Journals on Vocabulary Acquisition.Language Teaching Research, 13(4), 403423.https://www.google.com.tr/\#q=Vocabulary+Notebooks:+Implementation+an d+Outcomes 


\section{Appendix 1.}

\section{Interview Questions for the Administrators}

1. Why did you implement vocabulary journals into main course classes?

2. How did you come up with the idea of keeping vocabulary journals?

3. Did you get the opinions of the instructors before implementing it? If yes, what was their reaction?

4. What are your expectations on the learning outcomes of vocabulary journals?

The Vocabulary Journal Questionnaire for Main Course Instructors

1. What are your opinions with regard to vocabulary journals?

2. Has keeping vocabulary journals made any difference in students' vocabulary learning? If yes, what are those differences?

3. Have vocabulary journals improved students' retention of new words? If yes, how much improvement have you observed?

4. Do you think vocabulary journals will increase students' grades? Why or why not?

5. Do you think keeping vocabulary journals will be beneficial for the students when they proceed to their departments? Why or why not?

The Vocabulary Journal Questionnaire for New Students

Please circle the most appropriate option for each statement which corresponds most closely to your desired response.

1 = Strongly disagree, $2=$ Disagree, $3=$ Neither Agree nor Disagree, $4=$ Agree

$5=$ Strongly Agree

Vocabulary journal makes learning words easier.

$\begin{array}{lllll}1 & 2 & 3 & 4 & 5\end{array}$

Vocabulary journal is merely time- consuming for me.

$\begin{array}{lllll}1 & 2 & 3 & 4 & 5\end{array}$

Vocabulary journal helps me remember new words.

$\begin{array}{lllll}1 & 2 & 3 & 4 & 5\end{array}$

Keeping a vocabulary journal takes time, but it is worth the time spent.

$\begin{array}{lllll}1 & 2 & 3 & 4 & 5\end{array}$

Vocabulary journal encourages me to think about words.

$\begin{array}{lllll}1 & 2 & 3 & 4 & 5\end{array}$

Recording vocabulary systematically makes studying easier.

$\begin{array}{lllll}1 & 2 & 3 & 4 & 5\end{array}$

I never read the feedback my teacher gives me.

$\begin{array}{lllll}1 & 2 & 3 & 4 & 5\end{array}$

I find the feedback given by the teacher beneficial.

$\begin{array}{lllll}1 & 2 & 3 & 4 & 5\end{array}$

I believe I will get good marks from the vocabulary parts in the exams.

$\begin{array}{lllll}1 & 2 & 3 & 4 & 5\end{array}$

I will continue keeping a vocabulary journal when I proceed to my department.

$\begin{array}{lllll}1 & 2 & 3 & 4 & 5\end{array}$

I will not keep a vocabulary journal again.

$\begin{array}{lllll}1 & 2 & 3 & 4 & 5\end{array}$

I do not think keeping a vocabulary journal will increase my grades.

$\begin{array}{lllll}1 & 2 & 3 & 4 & 5\end{array}$ 
The Vocabulary Journal Questionnaire for Repeater Students

Please circle the most appropriate option for each statement which corresponds most closely to your desired response.

$1=$ Strongly disagree, $2=$ Disagree, $3=$ Neither Agree nor Disagree, $4=$ Agree

$5=$ Strongly Agree

Vocabulary journal has made learning words easier than it was last year.

$\begin{array}{lllll}1 & 2 & 3 & 4 & 5\end{array}$

Vocabulary journal is just merely time-consuming for me.

$\begin{array}{lllll}1 & 2 & 3 & 4 & 5\end{array}$

I can remember words better than I did last year.

$\begin{array}{lllll}1 & 2 & 3 & 4 & 5\end{array}$

Keeping a vocabulary journal takes time, but it is worth the time spent.

$\begin{array}{lllll}1 & 2 & 3 & 4 & 5\end{array}$

Vocabulary journal encourages me to think about words.

$\begin{array}{lllll}1 & 2 & 3 & 4 & 5\end{array}$

Recording vocabulary systematically has made studying easier than it was last year.

$\begin{array}{lllll}1 & 2 & 3 & 4 & 5\end{array}$

I find the feedback given by the teacher beneficial.

$\begin{array}{lllll}1 & 2 & 3 & 4 & 5\end{array}$

I believe I will get better marks than I did last year from the vocabulary parts in the exams.

$\begin{array}{lllll}1 & 2 & 3 & 4 & 5\end{array}$

I will continue keeping a vocabulary journal when I proceed to my department.

$\begin{array}{lllll}1 & 2 & 3 & 4 & 5\end{array}$

I do not think keeping a vocabulary journal has made any difference for me in terms of learning words.

$\begin{array}{lllll}1 & 2 & 3 & 4 & 5 \\ \text { I will not keep a vocabulary journal again. }\end{array}$

$\begin{array}{lllll}1 & 2 & 3 & 4 & 5\end{array}$ 